\title{
Incretin Therapy for Type 2 Diabetes in Spain: A Cost-Effectiveness Analysis of Liraglutide Versus Sitagliptin
}

Pedro Mezquita Raya • Antonio Pérez • Antonio Ramírez de Arellano •

Teresa Briones • Barnaby Hunt • William J. Valentine

To view enhanced content go to www.diabetestherapy-open.com

Received: August 27, 2013 / Published online: October 17, 2013

(c) The Author(s) 2013. This article is published with open access at Springerlink.com

\section{ABSTRACT}

Introduction: Treatment with glucagon-like peptide-1 receptor agonists and dipeptidyl peptidase-4 inhibitors, which target the incretin axis, has the potential to improve glycemic control in type 2 diabetes patients without the weight gain associated with traditional therapies. To evaluate the relative cost-effectiveness of incretin therapies, the

\section{P. Mezquita Raya}

Clinica San Pedro, Hospital Torrecardenas, Almería, Spain

\section{A. Pérez}

Hospital de la Santa Creu i Sant Pau, Barcelona, Spain

A. Ramírez de Arellano ( $\square)$ · T. Briones Novo Nordisk, C/Via de los Poblados, 3, Parque Empresarial Cristalia, 28033 Madrid, Spain e-mail: area@novonordisk.com

B. Hunt · W. J. Valentine

Ossian Health Economics and Communications, Basel, Switzerland

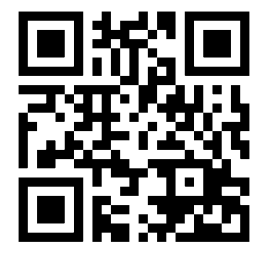

Enhanced content for this article is available on the journal web site: www.diabetestherapy-open.com present study aimed to compare the long-term clinical and cost implications associated with liraglutide and sitagliptin in type 2 diabetes patients in Spain.

Methods: Data were taken from a randomized, controlled trial (NCT00700817) in which adults with type 2 diabetes failing metformin monotherapy were randomly allocated to receive either liraglutide $1.2 \mathrm{mg}$ or sitagliptin $100 \mathrm{mg}$ daily in addition to metformin. Longterm projections of clinical outcomes and direct costs (2012 EUR) based on observed treatment effects were made using a published and validated type 2 diabetes model. Costs were taken from published sources. Future costs and clinical benefits were discounted at $3 \%$ annually. Sensitivity analyses were performed.

Results: Liraglutide was associated with improved discounted life expectancy (14.05 versus 13.91 years) and quality-adjusted life expectancy [9.04 versus 8.87 quality-adjusted life years (QALYs)] compared to sitagliptin. Improved clinical outcomes were driven by improved glycemic control, leading to reduced incidence of diabetes-related complications, including renal disease, cardiovascular disease, ophthalmic and diabetic foot complications. 
Liraglutide was associated with increased direct costs of EUR 2,297, yielding an incremental cost-effectiveness ratio of EUR 13,266 per QALY gained versus sitagliptin.

Conclusions: Liraglutide was projected to improve life expectancy, quality-adjusted life expectancy and reduce incidence of diabetesrelated complication. Liraglutide is likely to be cost-effective versus sitagliptin from a healthcare payer perspective in Spain.

Keywords: Cost; Cost-effectiveness; DPP-4; GLP-1; Incretin; Liraglutide; Sitagliptin; Spain; Type 2 diabetes

\section{INTRODUCTION}

Diabetes mellitus represents a significant and growing challenge to healthcare providers in Spain, with a current prevalence of $13.8 \%$, around half of which is undiagnosed, and almost $30 \%$ of the population has some form of carbohydrate metabolism disturbance [1]. The disease is associated with a significant clinical burden, both in terms of morbidity and mortality, with 19,518 deaths attributable to diabetes in Spain in 2010 [2]. Further to the clinical burden, the economic burden is also substantial. Current estimates suggest that diabetes is responsible for between $5 \%$ and $13 \%$ of total healthcare expenditure in most developed countries, and Spain is no exception [2]. Health care expenditure as a result of diabetes mellitus was estimated to be approximately USD 12.5 billion in Spain in 2010 (9\% of total healthcare expenditure), and projections suggest that this could increase to approximately USD 16.5 billion in 2030 [3]. The principle driver of this expenditure is diabetesrelated complications.

Whilst maintaining glycemic control forms the cornerstone of diabetes treatment, evidence suggests that controlling other risk factors is also important in reducing the long-term risk of complications. This includes serum lipid levels, blood pressure and body weight. The benefits of multifactorial intervention have been demonstrated in a number of trials, but particularly the Steno-2 study, which compared conventional treatment for multiple risk factors versus intensive multifactorial treatment [4-6]. Intensive treatment was associated with reduced risk of all-cause mortality, cardiovascular events, retinopathy, neuropathy and end-stage renal disease over 13 years of follow-up. Most long-established diabetes interventions are designed to improve glycemic control, but do little to address other risk factors and meet the multifaceted needs of the type 2 diabetes patient [7].

To meet these complex clinical needs, clinical development programs have targeted the modulation of incretin activity (gastrointestinal hormones involved in the regulation of gut motility, secretion of gastric acid and pancreatic enzymes, gall bladder contraction and nutrient absorption) [8]. This has led to the development of two new classes of antidiabetic therapy: degradation-resistant glucagon-like peptide-1 (GLP-1) receptor agonists, such as liraglutide and exenatide, and inhibitors of dipeptidyl peptidase-4 (DPP4), such as sitagliptin and vildagliptin. Data from published studies indicate that GLP-1 receptor agonists may be associated with a more substantial reduction in glycated hemoglobin (HbA1c) in comparison with DPP4 inhibitors $(0.5-1.6 \%$ reduction versus $0.5-1.0 \%$ reduction) [7]. Weight loss has been shown to be associated with liraglutide and exenatide treatment [9-14], whereas DPP-4 inhibitors are weight neutral and have been associated only with the prevention of weight gain [15-18]. 
Although there is a growing body of clinical data available on these new agents, and several health economic analyses have been published comparing them with long-established interventions, there is a paucity of data on the cost-effectiveness of GLP-1 receptor agonists in comparison with DPP-4 inhibitors. The aim of the present analysis was to assess the costeffectiveness of liraglutide versus sitagliptin, as add-on to metformin therapy, in patients failing metformin alone in the Spanish setting.

\section{METHODS}

\section{Simulated Cohort and Treatment Effects}

In 2010, Pratley et al. [9] reported a parallelgroup, open-label trial in participants (aged 18-80 years) with type 2 diabetes mellitus who had inadequate glycemic control (HbA1c 7.5-10.0\%) on metformin ( $\geq 1,500 \mathrm{mg}$ daily for $\geq 3$ months) designed to compare the efficacy and safety of liraglutide and sitagliptin. Patients were randomly allocated to $1.2 \mathrm{mg}$ subcutaneous liraglutide once daily $(n=225)$, or $100 \mathrm{mg}$ oral sitagliptin once daily $(n=219)$ at sites in Europe (including 9 centers and 32 participants in Spain) and North America. Main exclusion criteria included body mass index over $45 \mathrm{~kg} / \mathrm{m}^{2}$, previous treatment with any antihyperglycemic agent apart from metformin within 3 months of the trial, recurrent major hypoglycemia or hypoglycemic unawareness, present use of any drug except metformin that could affect glucose metabolism, impaired renal or hepatic function, clinically significant cardiovascular disease, or cancer. Baseline patient cohort characteristics, based on the population enrolled in the study, are shown Table 1.

After 26 weeks of follow-up, both liraglutide and sitagliptin were associated with improvements in HbA1c, systolic blood
Table 1 Baseline characteristics of the simulation cohort

\begin{tabular}{ll}
\hline Characteristic & Value, mean (SD) \\
\hline Age (years) & $55.3(9.2)$ \\
Duration of diabetes (years) & $6.0(4.5)$ \\
Males (\%) & 52.9 \\
HbAlc $\%)$ & $8.4(0.8)$ \\
SBP $(\mathrm{mmHg})$ & $132.2(14.6)$ \\
Total cholesterol $(\mathrm{mmol} / \mathrm{L})$ & $4.09(1.14)$ \\
HDL cholesterol $(\mathrm{mmol} / \mathrm{L})$ & $1.16(0.31)$ \\
LDL cholesterol $(\mathrm{mmol} / \mathrm{L})$ & $2.65(0.82)$ \\
Triglycerides $(\mathrm{mmol} / \mathrm{L})$ & $2.38(2.22)$ \\
Body mass index $\left(\mathrm{kg} / \mathrm{m}^{2}\right)$ & $32.8(5.2)$ \\
Smokers $(\%)$ & 29.5
\end{tabular}

Baseline characteristics are the weighted mean of patients enrolled in the liraglutide $1.2 \mathrm{mg}$ and sitagliptin arms of the study

HbAlc glycated hemoglobin, $H D L$ high-density lipoprotein, $L D L$ low-density lipoprotein, $S D$ standard deviation, $S B P$ systolic blood pressure

pressure, blood lipid levels and body mass index (BMI). Treatment effects were applied in the first year of the analysis based on the clinical trial data (Table 2). Hypoglycemia rates were similar in the two arms of the trial, although one major hypoglycemic event was reported in the liraglutide arm, but none in the sitagliptin arm. Patients were assumed to receive liraglutide or sitagliptin for 5 years, before intensifying treatment to basal insulin (incretin therapy withdrawn). On treatment intensification, BMI was assumed to return to baseline and hypoglycemia event rates were assumed to be the same, but no other treatment effects were applied.

\section{Model Description}

The analysis was performed using the CORE Diabetes Model (IMS Health, Basel, 
Table 2 Treatment effects applied in the first year of the analysis

\begin{tabular}{|c|c|c|c|}
\hline Physiological parameter & $\begin{array}{l}\text { Liraglutide } 1.2 \mathrm{mg} \text {, } \\
\text { mean }(S D)\end{array}$ & $\begin{array}{l}\text { Sitagliptin } 100 \mathrm{mg} \text {, } \\
\text { mean (SD) }\end{array}$ & Difference \\
\hline Change in $\mathrm{HbAlc}(\%)$ & $-1.24(1.02)$ & $-0.90(1.01)$ & $-0.34^{*}$ \\
\hline Change in SBP (mmHg) & $-0.55(12.99)$ & $-0.94(12.99)$ & 0.39 \\
\hline Change in total cholesterol $(\mathrm{mmol} / \mathrm{L})$ & $-0.03(0.82)$ & $-0.02(0.80)$ & -0.01 \\
\hline Change in HDL cholesterol (mmol/L) & $0.00(0.17)$ & $0.00(0.17)$ & 0.00 \\
\hline Change in LDL cholesterol $(\mathrm{mmol} / \mathrm{L})$ & $0.08(0.69)$ & $0.13(0.68)$ & -0.05 \\
\hline Change in triglycerides $(\mathrm{mmol} / \mathrm{L})$ & $-0.19(1.42)$ & $-0.40(1.38)$ & 0.21 \\
\hline Change in body mass index $\left(\mathrm{kg} / \mathrm{m}^{2}\right)$ & $-0.99(1.37)$ & $-0.33(1.37)$ & $-0.66^{*}$ \\
\hline Major hypoglycemic events (per 100 patient years) & 1.00 & 0.00 & 1.00 \\
\hline Minor hypoglycemic events (per 100 patient years) & 17.80 & 10.60 & 7.20 \\
\hline
\end{tabular}

Switzerland), the architecture, assumptions, features and capabilities of which have been previously published [10]. The model is a validated, non-product-specific diabetes policy analysis tool and is based on a series of interdependent sub-models that simulate the complications of diabetes (angina, myocardial infarction, congestive heart failure, stroke, peripheral vascular disease, diabetic retinopathy, macular edema, cataract, hypoglycemia, ketoacidosis, lactic acidosis, nephropathy and end-stage renal disease, neuropathy, foot ulcer and amputation, and non-specific mortality). Each sub-model has a semi-Markov structure and uses time, state, time-in-state and diabetes type-dependent probabilities derived from published sources. Monte Carlo simulation using tracker variables overcomes the memory-less properties of the standard Markov model, and allows interconnectivity and interaction between individual complication sub-models. Longterm outcomes projected by the model have been validated against real life data in 2004 and more recently in 2012 [11, 12].

\section{Costs and Utilities}

Costs were accounted from the perspective of a healthcare payer in Spain (i.e., Sistema Nacional de Salud) in 2012 Euros (EUR). The Spanish health system has the characteristics of the "Beveridge Model" since it is mostly funded by direct taxation, it covers the resident population on the basis of citizenship and the provision of services is mostly made by public units. The costs of diabetes medications, selfmonitoring of blood glucose, concomitant medications (statins, aspirin and angiotensinconverting enzyme inhibitors), and diabetesrelated complications were captured. Costs were identified through literature review and came from diagnosis-related group tariffs released by the Spanish Ministry for Health, and published cost collection studies, with inflation to 2012 values as required [13-21]. Health-related 
quality of life utilities associated with diabetesrelated complications were as per a previous cost-effectiveness analysis of liraglutide versus sitagliptin, carried out in the UK setting [22].

\section{Statistical Approach and Other Model Settings}

A simulated cohort of 1,000 patients was run through the model 1,000 times for each simulation (base case and sensitivity analysis). Mean values and standard deviations were generated for long-term outcomes. A total of 1,000 mean values (each from 1,000 patients) of incremental direct medical costs and incremental effectiveness in terms of qualityadjusted life expectancy were plotted (scatterplots) on a cost-effectiveness plane. Subsequently, acceptability curves were generated by calculating the proportion of points below a range of willingness to pay thresholds (up to EUR 100,000 per QALY gained). The time horizon was set to patient lifetimes in the base case to capture all relevant long-term complications and associated costs, to assess their impact on life expectancy and quality-adjusted life expectancy. Future costs and clinical benefits were discounted symmetrically by $3 \%$ per annum in line with published health economic guidance for Spain [23].

\section{Sensitivity Analyses}

A series of one-way sensitivity analyses were conducted to identify key drivers of outcomes and assess the robustness of results of the base case analysis. The influence of time horizon on the outcomes projected by the model was investigating by running analyses over 5, 10, 20 and 30 years, compared to 50 years in the base case. Similarly, the effect of discount rates on future costs and clinical outcomes were investigated through analyses in which they were set (symmetrically) to $0 \%$ and $5 \%$ per annum. The effect of over- or underestimating the unit costs of diabetes complications used in the analysis was evaluated in two sensitivity analyses, which increased and decreased the values used by $10 \%$ from the base case costs. The importance of changes in physiological parameters were investigated in four sensitivity analysis, in which benefits in HbA1c, systolic blood pressure, blood lipids and BMI were individually abolished. A further analysis was conducted in which HbA1c was assumed to progress according to the UK Prospective Diabetes Study (UKPDS) progression curve before switching to basal insulin. The effect of the timing of treatment switching was examined by varying the treatment switch to 7 and 3 years in the liraglutide arm.

As part of the follow-up to the clinical trial, patients receiving sitagliptin were given the option of switching to liraglutide following completion of the initial study period [24]. Patients were then followed for a further 26 weeks. On switching to $1.2 \mathrm{mg}$ liraglutide, improvements were seen in HbA1c, systolic blood pressure, blood lipid profiles and BMI, in addition to the changes seen on starting sitagliptin therapy. An analysis was conducted in which patients received sitagliptin for 1 year, and then switched to liraglutide. As in the base case, patients switched to basal insulin after 5 years of incretin therapy.

\section{Compliance with Ethics}

This article does not contain any studies with human or animal subjects performed by any of the authors. 
Table 3 Cost-effectiveness outcomes of the base case analysis

\begin{tabular}{llll}
\hline & $\begin{array}{l}\text { Liraglutide 1.2 mg, } \\
\text { mean (SD) }\end{array}$ & $\begin{array}{l}\text { Sitagliptin 100 mg, } \\
\text { mean (SD) }\end{array}$ & Difference \\
\hline Undiscounted life expectancy (years) & $20.00(0.33)$ & $19.72(0.30)$ & 0.28 \\
Discounted life expectancy (years) & $14.05(0.19)$ & $13.91(0.17)$ & 0.14 \\
Discounted quality-adjusted life expectancy (QALYs) & $9.04(0.13)$ & $8.87(0.11)$ & 0.17 \\
Discounted direct costs (EUR) & $54,684(1,250)$ & $52,387(1,346)$ & 2,297 \\
ICER (EUR per QALY gained) & 13,266 & & \\
\hline
\end{tabular}

EUR 2012 Euros, ICER incremental cost-effectiveness ratio, QALY quality-adjusted life year, $S D$ standard deviation

\section{RESULTS}

\section{Base Case}

Therapy with once daily liraglutide $1.2 \mathrm{mg}$ was associated with a mean undiscounted life expectancy of 20.00 years (SD 0.33) compared to 19.72 years (0.30) with once daily $100 \mathrm{mg}$ sitagliptin (Table 3). Analysis of discounted life expectancy showed a similar pattern, with liraglutide associated with a statistically significant increase of 0.14 years compared to sitagliptin (14.05 versus 13.91 years). Liraglutide was also associated with increased mean qualityadjusted life expectancy, from 8.87 qualityadjusted life years (QALYs) (95\% confidence interval 8.86-8.88 QALYs) with sitagliptin to 9.04 QALYs (95\% confidence interval 9.03-9.05 QALYs). These clinical benefits were primarily driven by improved glycemic control leading to a reduced incidence of diabetes-related complications in the liraglutide arm. End-stage complications, including severe vision loss, endstage renal disease, amputation and myocardial infarction, had the greatest impact on patient health-related quality of life, and the cumulative incidence of these complications showed significant reductions in the liraglutide arm. This included macrovascular complications, with the cumulative incidence of myocardial infarction reduced from $27 \%$ to $25 \%$, and microvascular complications, with the cumulative incidence of background diabetic retinopathy reduced from $17 \%$ to $15 \%$. The only complication that showed an increased incidence in the liraglutide arm was stroke. As well as a reduced incidence of complications, liraglutide was also associated with delayed onset of complications, with the mean time free of all complications increased by almost 7 months. Of particular note was the mean time to onset of stroke, which was delayed by 9 months in the liraglutide arm, demonstrating the influence of the survival paradox.

Direct costs were projected to increase by EUR 2,297 per patient in the liraglutide arm (EUR 54,684 in the liraglutide arm versus EUR 52,387 in the sitagliptin arm) (Table 3; Fig. 1). This increase was driven by the increased acquisition costs of liraglutide compared to sitagliptin in the first 5 years of the simulation. However, this was partially offset by the reduced costs of treating diabetesrelated complications. The most notable savings were made as a result of avoided neuropathy complications, where treatment with liraglutide was associated with cost savings of EUR 1,110 per patient. Based on these estimates, liraglutide was associated with an incremental costeffectiveness ratio (ICER) of EUR 13,266 per 


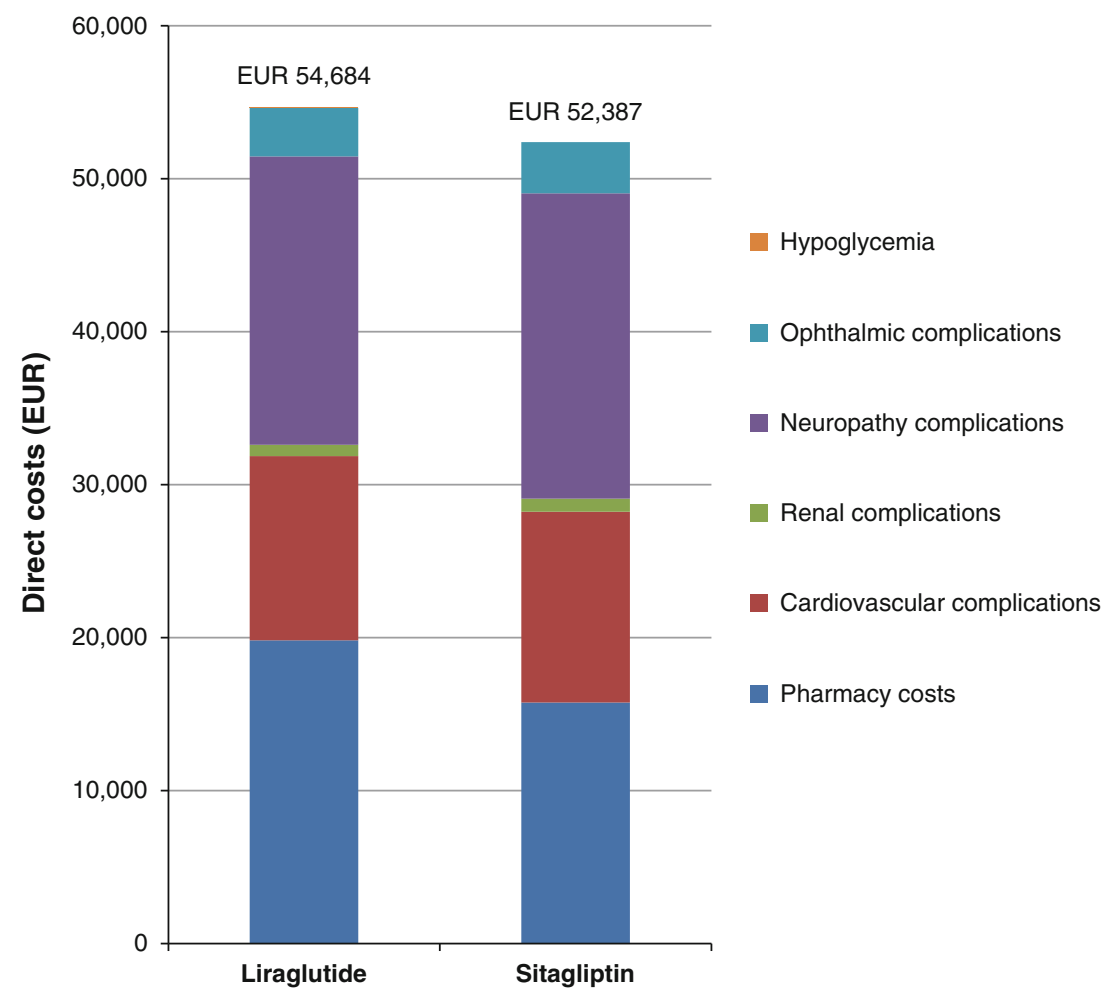

Fig. 1 Discounted direct medical costs associated with liraglutide and sitagliptin over patient lifetimes. EUR 2012 Euros

QALY gained compared to sitagliptin in Spain. This is below the commonly quoted willingness to pay threshold of EUR 30,000 per QALY gained. A scatterplot presenting the incremental costs versus incremental effectiveness for liraglutide versus sitagliptin shows 1,000 mean values, each representing a cohort of 1,000 patients run through the model is shown in Fig. 2. Data from the scatterplot was used to generate an acceptability curve, which showed that at a willingness to pay threshold of EUR 30,000 per QALY gained, there was a 73\% probability that liraglutide would be costeffective in comparison with sitagliptin.

\section{Sensitivity Analyses}

Sensitivity analyses found that costeffectiveness outcomes were most sensitive to changes in the HbA1c benefit associated with liraglutide (Table 4). When this benefit was abolished the ICER was found to increase to EUR 199,114 per QALY gained. The impact of changes in HbA1c was also demonstrated in the analysis in which the UKPDS progression curve was used. The ICER increased to EUR 29,012 per QALY gained, remaining below the EUR 30,000 per QALY gained threshold, as the HbA1c benefit in the liraglutide arm was not sustained. Changes in other physiological parameters had smaller impacts on the ICER, although making BMI changes equal in the two arms increased the ICER to EUR 16,931 per QALY gained.

Shortening the time horizon also had a significant impact on the ICER. This was primarily due to the fact that improvements in physiological parameters associated with 


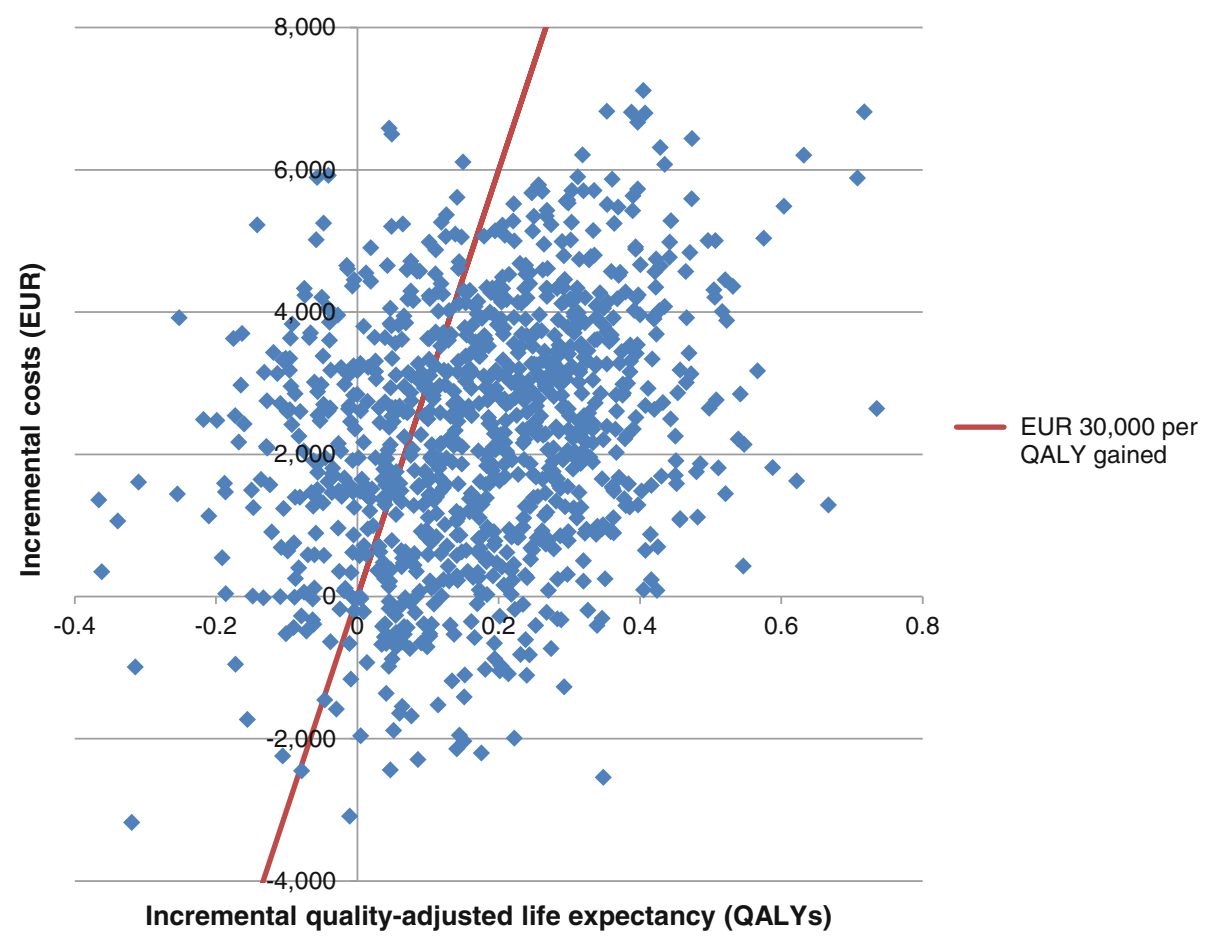

Fig. 2 Scatterplot of incremental costs versus incremental effectiveness of liraglutide $1.2 \mathrm{mg}$ versus sitagliptin. EUR 2012 Euros, QALY quality-adjusted life year

liraglutide reduce the risk of long-term complications, and the benefits of this are not fully realized over shorter time horizons. Interestingly, over a 30-year time horizon, the ICER was lower than in the base case analysis (50-year time horizon). This is due to the increased survival in the liraglutide arm, increasing mean life expectancy, and therefore greater costs are accrued in the liraglutide arm in the later years of the analysis. Altering the discount rate also reflected the long-term benefits associated with liraglutide, with incremental quality-adjusted life expectancy increasing to 0.29 QALYs and incremental costs falling to EUR 1,877 when a discount rate of $0 \%$ was used. Changing the timing of treatment switching led to changes in the ICER. It was found to increase when patients received incretin therapy for 7 years, due to the increased acquisition costs of liraglutide, and fell when treatment switching was brought forward. Increasing the cost of complications led to a small decrease in the ICER, whilst the converse was true when the cost of complications was reduced.

Switching patients to liraglutide after 1 year of sitagliptin treatment was found to improve clinical outcomes compared to remaining on sitagliptin. Mean life expectancy was increased by 0.11 years, and quality-adjusted life expectancy by 0.13 QALYs (Table 4). However, these increases compared to sitagliptin were not as large as in the base case analysis, where patients received liraglutide in the first year of the analysis. This was driven by smaller improvements in physiological parameters on delayed initiation of liraglutide compared to immediate initiation. Direct costs were higher in the delayed liraglutide arm than in the sitagliptin arm (EUR 54,444 versus 
Table 4 Summary of results of sensitivity analyses

\begin{tabular}{|c|c|c|c|c|c|c|c|}
\hline \multirow[t]{2}{*}{ Analysis } & \multicolumn{3}{|c|}{$\begin{array}{l}\text { Discounted quality-adjusted } \\
\text { life expectancy (QALYs) }\end{array}$} & \multicolumn{3}{|c|}{$\begin{array}{l}\text { Discounted direct } \\
\text { costs (EUR) }\end{array}$} & \multirow{2}{*}{$\begin{array}{l}\text { ICER } \\
\text { (EUR } \\
\text { per QALY } \\
\text { gained) }\end{array}$} \\
\hline & $\begin{array}{l}\text { Liraglutide } \\
1.2 \mathrm{mg}\end{array}$ & $\begin{array}{l}\text { Sitagliptin } \\
100 \mathrm{mg}\end{array}$ & Difference & $\begin{array}{l}\text { Liraglutide } \\
1.2 \mathrm{mg}\end{array}$ & $\begin{array}{l}\text { Sitagliptin } \\
100 \mathrm{mg}\end{array}$ & Difference & \\
\hline Base case & 9.04 & 8.87 & 0.17 & 54,684 & 52,387 & 2,297 & 13,266 \\
\hline 30-year time horizon & 8.89 & 8.72 & 0.17 & 51,435 & 49,219 & 2,216 & 12,813 \\
\hline 20-year time horizon & 8.05 & 7.92 & 0.13 & 41,822 & 39,270 & 2,552 & 19,495 \\
\hline 10-year time horizon & 5.36 & 5.30 & 0.06 & 23,431 & 20,029 & 3,402 & 58,433 \\
\hline 5-year time horizon & 3.07 & 3.04 & 0.04 & 13,309 & 9,507 & 3,802 & 102,605 \\
\hline $0 \%$ discount rate & 12.58 & 12.30 & 0.29 & 85,633 & 83,755 & 1,877 & 6,547 \\
\hline $5 \%$ discount rate & 7.50 & 7.37 & 0.13 & 42,626 & 40,181 & 2,445 & 18,753 \\
\hline $\begin{array}{l}\text { Costs of complications } \\
\text { plus } 10 \%\end{array}$ & 9.04 & 8.87 & 0.17 & 58,268 & 56,147 & 2,121 & 12,248 \\
\hline $\begin{array}{l}\text { Costs of complications } \\
\text { minus } 10 \%\end{array}$ & 9.04 & 8.87 & 0.17 & 51,277 & 48,805 & 2,473 & 14,279 \\
\hline No HbAlc difference & 8.89 & 8.87 & 0.02 & 56,315 & 52,387 & 3,928 & 199,114 \\
\hline No SBP difference & 9.04 & 8.87 & 0.18 & 54,672 & 52,387 & 2,285 & 13,087 \\
\hline No lipid difference & 9.04 & 8.87 & 0.17 & 54,683 & 52,387 & 2,296 & 13,288 \\
\hline No BMI difference & 9.00 & 8.87 & 0.14 & 54,675 & 52,387 & 2,288 & 16,931 \\
\hline No hypoglycemia difference & 9.05 & 8.87 & 0.18 & 54,758 & 52,387 & 2,371 & 13,127 \\
\hline $\begin{array}{l}\text { UKPDS creep for } \\
5 \text { years }\end{array}$ & 8.71 & 8.59 & 0.11 & 59,289 & 55,991 & 3,297 & 29,012 \\
\hline $\begin{array}{l}\text { Treatment switch } \\
\text { after } 7 \text { years }\end{array}$ & 9.05 & 8.87 & 0.18 & 55,889 & 52,387 & 3,502 & 19,019 \\
\hline $\begin{array}{l}\text { Treatment switch after } \\
3 \text { years }\end{array}$ & 9.02 & 8.87 & 0.16 & 53,339 & 52,387 & 952 & 6,115 \\
\hline $\begin{array}{l}\text { Receive sitagliptin } \\
\text { for } 1 \text { year before } \\
\text { switching to liraglutide }\end{array}$ & 8.99 & 8.87 & 0.13 & 54,444 & 52,387 & 2,057 & 16,287 \\
\hline
\end{tabular}

EUR 2012 Euros, HbAlc glycated hemoglobin, ICER incremental cost-effectiveness ratio, QALY quality-adjusted life year, SBP systolic blood pressure, UKPDS United Kingdom Prospective Diabetes Study

EUR 52,387). As in the base case, increased costs were driven by the acquisition of liraglutide in years two to five of the analysis, but were partially offset by the reduced cost of treating diabetes-related complications. The ICER of EUR 16,287 per QALY gained is higher than in the base case analysis. The results of this subanalysis, in conjunction with the base case, indicate that starting patients on liraglutide earlier is associated with improved outcomes compared to the delayed initiation scenario, and does so at a lower ICER. Initiating 
liraglutide earlier shows extended dominance over delaying initiation of liraglutide therapy by 1 year.

\section{DISCUSSION}

The present long-term cost-effectiveness modeling analysis indicates that liraglutide $1.2 \mathrm{mg}$ is associated with improved clinical outcomes, in terms of life expectancy, qualityadjusted life expectancy and avoidance of diabetes-related complications, in comparison to sitagliptin. Sensitivity analysis identified that improved glycemic control, manifest by reduced $\mathrm{HbA1c}$, is the key driver of the clinical benefit (as identified by the sensitivity analyses), but improvements in other physiological parameters play a role in reducing the long-term risk of diabetes-related complications. The increased incidence of stroke observed is likely to be due to the survival paradox, where an increased number of events are seen in the liraglutide arm due to the increased life expectancy. Liraglutide was associated with increased direct medical costs, driven by the acquisition cost of liraglutide but this was partially offset by the reduced cost of treating diabetes-related complications. Based on the calculated ICER, once daily $1.2 \mathrm{mg}$ liraglutide is likely to be cost-effective compared to one daily $100 \mathrm{mg}$ sitagliptin in Spain. A sub-group analysis found that delaying liraglutide therapy by 1 year resulted in less favorable clinical outcomes compared to initiating liraglutide earlier, although cost savings could be made as a result. The present analysis compares the $1.2 \mathrm{mg}$ daily dose of liraglutide with sitagliptin, as this is the most commonly prescribed dose in Europe. However, a $1.8 \mathrm{mg}$ daily dose is also available, and data from the clinical trial published by Pratley et al. [9] suggest that the higher dose may be associated with greater clinical benefits than the $1.2 \mathrm{mg}$ dose.

Whilst metformin remains the first-line therapy option for patient with type 2 diabetes, modulation of incretin activity, through addition of a GLP-1 receptor agonist or a DPP-4 inhibitor, represents a potential second-line therapy option for patients failing to achieve glycemic control on metformin monotherapy. The GLP-1 receptor agonists and DPP-4 inhibitors offer alternatives to longstanding second-line treatment options, such as sulphonylureas (associated with increased risk of hypoglycemic events and modest weight gain) or thiazolidinediones (associated with cardiovascular risk, weight gain, edema and fractures) [25]. Modern treatment of type 2 diabetes is based around maintaining glycemic control, but also addressing the comorbidities associated with diabetes, specifically obesity, hypertension and dyslipidemia and the trial data published by Pratley et al. [9] suggest that liraglutide and sitagliptin may be useful in terms of managing a variety of risk factors. Through maintaining this multifactorial control, the risk of long-term diabetes-related complications can be reduced, thereby reducing the burden of diabetes.

Previous cost-effectiveness analyses have compared GLP-1 receptor agonists and DPP-4 inhibitors with conventional second line treatments, but only two other published studies have compared liraglutide and sitagliptin. The results of the present analysis agree with these previous cost-effectiveness analyses, carried out from the perspective of healthcare payers in the United Kingdom and United States. Davies et al. [22] found that liraglutide was associated with an ICER of GBP 9,851 per QALY gained (below a willingness to pay threshold of GBP 20,000 per QALY gained threshold), while Lee et al. [26] 
calculated an ICER of USD 25,742 per QALY gained (below a willingness to pay threshold of USD 50,000 per QALY gained) versus sitagliptin. The results across the United Kingdom, United States and Spain suggest that liraglutide may be a cost-effective treatment option in all three settings.

The present analysis found that liraglutide was associated with reduced cumulative incidence and delayed onset of neuropathy compared to sitagliptin. There is evidence from animal models suggesting that increased circulating GLP-1 (either through administration of a DPP-4 inhibitor or a GLP-1 receptor agonist) may reduce neuropathy, independent of glycemic control [27]. However, this research is at a very early stage, and how the potential benefit will manifest in humans, rather than animals is, as yet, unknown.

A further consideration is how generalizable the population of the trial reported by Pratley et al. is to the Spanish setting. The diabetes mellitus group of the Sociedad Española de Endocrinología y Nutrición (Spain Endocrinology and Nutrition Society, SEEN) has conducted a retrospective study of GLP-1 receptor agonists in clinical practice [28]. The baseline characteristics of this real-world population match well to the baseline characteristics of the trial participants on which the present analysis is based, in terms of age, duration of diabetes, HbA1c, systolic blood pressure and blood lipid measurements. However, the BMI of patients currently receiving liraglutide in Spain is a little higher than in the clinical trial $\left(38.0 \mathrm{~kg} / \mathrm{m}^{2}\right.$ compared to $32.8 \mathrm{~kg} / \mathrm{m}^{2}$ ). It may be the case that liraglutide will be associated with greater weight loss in these patients, and therefore liraglutide may be more cost-effective in this population.
A potential limitation of the analysis may be the robustness of the input data from the clinical trials. Both the original study and the extension study where the patients were switched from sitagliptin to liraglutide were open-label trials, owing to the nature of comparison of an oral agent with an injection. This may have led to patients having different expectations of the effects of liraglutide or sitagliptin, which potentially may have influenced adherence to lifestyle recommendations. Although the extent of any such effect is difficult to assess, it is reassuring that the efficacy findings are in line with the results of other head-to-head trials comparing GLP-1 receptor agonists with DPP-4 inhibitors. For example, when exenatide once-weekly (Diabetes Therapy Utilization: Researching Changes in A1C 2, DURATION-2) or taspoglutide (T-emerge 4) were compared with sitagliptin over 26 weeks, HbA1c was reduced by $1.5 \%$ and $1.3 \%$ with exenatide once-weekly and taspoglutide, respectively, compared with $0.9 \%$ with sitagliptin $[29,30]$. Weight loss with sitagliptin was a little better in the Pratley et al. [9] trial than in previous studies where it has been generally shown to be weight neutral.

The impact of adherence to the two diabetes medications evaluated should be considered. Whilst adherence to alternative GLP-1 receptor agonists has been assessed, currently, there is no evidence to suggest that injectable GLP-1 receptor agonists are associated with lower adherence rates than oral DPP-4 inhibitors [31, 32]. Moreover, the impact of adherence on costeffectiveness is difficult to assess, as both clinical outcomes and costs will be affected by adherence rates.

A further limitation of the present analysis is the reliance on short-term clinical data in making long-term predictions of outcomes over time horizons of up to 50 years. However, 
this is a limitation inherent to most costeffectiveness modeling studies, and despite this, such studies represent one of the best available options for making estimates of longterm clinical and economic outcomes in the absence of long-term clinical data. The generalizability of the risk equations used in modeling analyses must also be considered, with data (such as that from the UKPDS) now historic and perhaps not representative of modern diabetes treatment in Spain. As a result, there is unavoidable uncertainty around how well the modeling analysis represents the real world. The present study aims to minimize this limitation, through use of a recently validated model to conduct the analysis, and basing changes in physiological parameters on data collected in a randomized controlled trial $[9,11,12]$. Furthermore, the use of QALYs in health economic analysis remains a somewhat controversial issue. Some argue that assumptions that underlie the QALY concept are often broken, and other measures (such as the healthy year equivalent) are more appropriate [33]. The Glycemia Reduction Approaches in Diabetes (GRADE) study will aim to provide long-term data on the relative effectiveness of diabetes medications in patients failing metformin therapy, including liraglutide and sitagliptin [34]. This 5,000-patient, 7-year study will provide a wealth of data for health economic analysis, and will be a key data source for future economic evaluation when the study reports in 2020 .

\section{CONCLUSION}

The recent 26-week study investigating the safety and efficacy of liraglutide and sitagliptin published by Pratley et al. [9] indicated that liraglutide was associated with greater improvements from baseline $\mathrm{HbA1c}$, total cholesterol and BMI compared to sitagliptin. Long-term projections of this short-term trial data using a recently validated model suggest that liraglutide is likely to improve survival, reduce complication rates and be cost-effective from the perspective of a healthcare payer in Spain.

\section{ACKNOWLEDGMENTS}

Dr. Ramírez de Arellano is the guarantor for this article, and takes responsibility for the integrity of the work as a whole. Sponsorship and the article processing charge for this study were funded by Novo Nordisk.

Conflict of interest. Pedro Mezquita Raya and Antonio Pérez are scientific collaborators with Novo Nordisk and have participated in advisory boards and clinical trials. Antonio Ramírez de Arellano and Teresa Briones are employees of Novo Nordisk. Barnaby Hunt and William Valentine are employees of Ossian Health Economics and Communications, which received a consulting fee from Novo Nordisk to support the study.

Compliance with ethics. This article does not contain any studies with human or animal subjects performed by any of the authors.

Open Access. This article is distributed under the terms of the Creative Commons Attribution Noncommercial License which permits any noncommercial use, distribution, and reproduction in any medium, provided the original author(s) and the source are credited. 


\section{REFERENCES}

1. Soriguer F, Goday A, Bosch-Comas A, et al. Prevalence of diabetes mellitus and impaired glucose regulation in Spain: the Di@bete.es study. Diabetologia. 2012;55:88-93.

2. International Diabetes Federation. IDF diabetes atlas. 5th ed. Brussels: International Diabetes Federation; 2011.

3. Zhang P, Zhang X, Brown J, et al. Global healthcare expenditure on diabetes for 2010 and 2030 . Diabetes Res Clin Pract. 2010;87:293-301.

4. Gaede P, Vedel P, Larsen N, Jensen GV, Parving HH, Pedersen O. Multifactorial intervention and cardiovascular disease in patients with type 2 diabetes. N Engl J Med. 2003;348:383-93.

5. Gaede P, Lund-Andersen H, Parving HH, Pedersen O. Effect of a multifactorial intervention on mortality in type 2 diabetes. N Engl J Med. 2008;358:580-91.

6. Gaede P, Valentine WJ, Palmer AJ, et al. Costeffectiveness of intensified versus conventional multifactorial intervention in type 2 diabetes: results and projections from the Steno-2 study. Diabetes Care. 2008;31:1510-5.

7. Nathan DM, Buse JB, Davidson MB, et al. Management of hyperglycemia in type 2 diabetes: a consensus algorithm for the initiation and adjustment of therapy: a consensus statement from the American Diabetes Association and the European Association for the Study of Diabetes. Diabetes Care. 2006;29:1963-72.

8. Drucker DJ, Nauck MA. The incretin system: glucagon-like peptide-1 receptor agonists and dipeptidyl peptidase-4 inhibitors in type 2 diabetes. Lancet. 2006;368:1696-705.

9. Pratley RE, Nauck M, Bailey T, the 1860-LIRA-DPP-4 Study Group, et al. Liraglutide versus sitagliptin for patients with type 2 diabetes who did not have adequate glycaemic control with metformin: a 26-week, randomised, parallel-group, open-label trial. Lancet. 2010;375:1447-56.

10. Palmer AJ, Roze S, Valentine WJ, et al. The CORE Diabetes Model: projecting long-term clinical outcomes, costs and cost-effectiveness of interventions in diabetes mellitus (types 1 and 2) to support clinical and reimbursement decisionmaking. Curr Med Res Opin. 2004;20(Suppl 1):5-26.

11. Palmer AJ, Roze S, Valentine W, et al. Validation of the CORE Diabetes Model against epidemiological and clinical studies. Curr Med Res Opin. 2004;20(Suppl 1):27-40.
12. Foos V, Palmer JL, Grant D, Lloyd A, Lamotte M, McEwan P. PRM58 long-term validation of the IMS CORE Diabetes Model in type 1 and type 2 diabetes. Value Health. 2012;15:A470.

13. Levy E, Gabriel S, Dinet J. The comparative medical costs of atherothrombotic disease in European countries. Pharmacoeconomics. 2003;21:651-9.

14. Arós F, Loma-Osorio A, Alonso A, et al. Guías de actuación clínica de la Sociedad Española de Cardiología en el infarto agudo de miocardio. Rev Esp Cardiol. 1999;52:919-56.

15. Lopez-Bastida J, Aguilar S, Alvarez M, Gonzalez D. The economic burden of stroke in Spain. Value Health. 2003;6:615.

16. Arrieta J. Evaluación económica del tratamiento sustitutivo renal (hemodiálisis, diálisis peritoneal y trasplante) en España. Nefrologia. 2010;1(Supl Ext $1): 37-47$.

17. Hammer M, Lammert M, Mejías SM, Kern W, Frier BM. Costs of severe hypoglycaemia in three European countries. J Med Econ. 2009;12:281-90.

18. Curtis JR, To T, Muirhead S, Cummings E, Daneman D. Recent trends in hospitalization for diabetic ketoacidosis in Ontario children. Diabetes Care. 2002;25:1591-6.

19. Oliva J, Lobo F, Molina B, Monereo S. Estudio de los costes directos sanitarios de los pacientes con diabetes mellitus en España. Diabetes Care. 2004;27:2616-21.

20. Castells X, Alonso J, Castilla M, Ribó C, Cots F, Antó $\mathrm{JM}$. Outcomes and costs of outpatient and inpatient cataract surgery: a randomised clinical trial. J Clin Epidemiol. 2001;54:23-9.

21. Ministerio de Sanidad, Politica Social e Igualdad, Grupos Relacionados de Diagnóastico (GRD), 2008 http://www.msps.es/estadEstudios/estadisticas/docs/ PESOS_ESPANOLES_AP_GRD_V23_2008.pdf.

22. Davies MJ, Chubb BD, Valentine WJ. Cost-utility analysis of liraglutide compared with sulphonylurea or sitagliptin, all as add-on to metformin monotherapy in Type 2 diabetes mellitus. Diabet Med. 2012;29:313-20.

23. López-Bastida J, Oliva J, Antoñanzas F, et al. Spanish recommendations on economic evaluation of health technologies. Eur J Health Econ. 2010;11:513-20.

24. Pratley RE, Nauck MA, Bailey T, et al. Efficacy and safety of switching from the DPP-4 inhibitor sitagliptin to the human GLP-1 analog liraglutide after 52 weeks in metformin-treated patients with 
type 2 diabetes: a randomized, open-label trial. Diabetes Care. 2012;35:1986-93.

25. Inzucchi SE, Bergenstal RM, Buse JB, et al. Management of hyperglycemia in type 2 diabetes: a patient-centered approach: Position statement of the American Diabetes Association (ADA) and the European Association for the Study of Diabetes (EASD). Diabetes Care. 2012;35:1364-79.

26. Lee WC, Samyshkin Y, Langer J, Palmer JL. Longterm clinical and economic outcomes associated with liraglutide versus sitagliptin therapy when added to metformin in the treatment of type 2 diabetes: a CORE Diabetes Model analysis. J Med Econ. 2012;15(Suppl 2):28-37.

27. Jin HY, Liu WJ, Park JH, Baek HS, Park TS. Effect of dipeptidyl peptidase-IV (DPP-IV) inhibitor (Vildagliptin) on peripheral nerves in streptozotocin-induced diabetic rats. Arch Med Res. 2009;40:536-44.

28. Mezquita-Raya P, López de la Torre Casares M, Moreno Pérez O, D.M. Diabetes WorkGroup. Liraglutide in patients with DM2 and obesity previously treated with oral antidiabetic agents: eDM Spain SEEN Study. Abstract accepted at International Diabetes Federation World Diabetes Congress. December 2-6, 2013, Melbourne, Australia. Abstract number: ME-0182.

29. Bergenstal RM, Forti A, Chiasson J et al. Once weekly taspoglutide, a human GLP-1 analog, is superior to sitagliptin in improving glycaemic control and weight loss in patients with type 2 diabetes (T2D): results from the T-emerge 4 trial. Diabetes 2010;59(Suppl. 1):A16 (58-OR).

30. Bergenstal RM, Wysham C, MacConell L, et al. Efficacy and safety of exenatide once weekly versus sitagliptin or pioglitazone as an adjunct to metformin for treatment of type 2 diabetes (DURATION-2): a randomised trial. Lancet. 2010;376:431-9.

31. Malmenäs M, Bouchard JR, Langer J. Retrospective real-world adherence in patients with type 2 diabetes initiating once-daily liraglutide $1.8 \mathrm{mg}$ or twice-daily exenatide $10 \mu \mathrm{g}$. Clin Ther. 2013;35:795-807.

32. Pelletier EM, Pawaskar M, Smith PJ, Best JH, Chapman RH. Economic outcomes of exenatide vs liraglutide in type 2 diabetes patients in the United States: results from a retrospective claims database analysis. J Med Econ. 2012;15:1039-50.

33. Gafni A, Birch S, Mehrez A. Economics, health and health economics: HYEs (healthy-years equivalent) versus QALYs (quality-adjusted live-year). J Health Econ. 1993;12:325-39.

34. Nathan DM, Buse JB, Kahn SE, et al. Rationale and design of the glycemia reduction approaches in diabetes: a comparative effectiveness study (GRADE). Diabetes Care. 2013;36:2254-61. 